\title{
Analyzing Some of the Students' Mistakes through Solving Multiple Choice Questions of Chemistry in Vietnamese High School
}

\author{
Cao Cu Giac* \\ School of Natural Science Education, Vinh University, Vietnam \\ *Corresponding author: giaccc@vinhuni.edu.vn
}

Received July 26, 2019; Revised August 28, 2019; Accepted September 08, 2019

\begin{abstract}
Using the results from students' mistakes to make interferential options (confused plans) in multiple choice questions will help teachers analyze the wrong situations and take corrective measures. With the learner's error-based teaching method, students will remember their mistakes and avoid repeating the same mistakes in learning. Multiple choice questions are widely used in the annual National High School Exam in Vietnam. However, in order to assess students' mistakes in the process of organizing teaching and learning in high schools, the design of multiple choice questions should focus on the results of the interferential options. From analyzing the results from wrong situations, the interferential options are strong enough to assess the impact from mistakes.
\end{abstract}

Keywords: students' mistakes, mistake-based teaching, erroneous analysis, multiple choice question, interferential option, chemistry

Cite This Article: Cao Cu Giac, “Analyzing Some of the Students' Mistakes through Solving Multiple Choice Questions of Chemistry in Vietnamese High School.” American Journal of Educational Research, vol. 7, no. 1 (2019): 618-623. doi: 10.12691/education-7-9-3.

\section{Introduction}

Many authors have in-depth studies of mistakes in teaching around the world, one of which is Richard M. Felder, North Carolina State University and Rebecca Brent, USA. In these studies, the author has pointed out the ten most important mistakes to be made in the teaching of teachers. One of the most dangerous mistakes he made was that teaching teachers had no clear goals, disrespect and interaction with students, did not grasp the psychology of learners, and did not know if they could make mistakes in the learning process [1].

According to Keith Taber, the different types of mistakes that have a method of impacting students to overcome mistakes are different - Figure 1 [2] "Students think and learn in science: views on nature and the development of learners' ideas”.

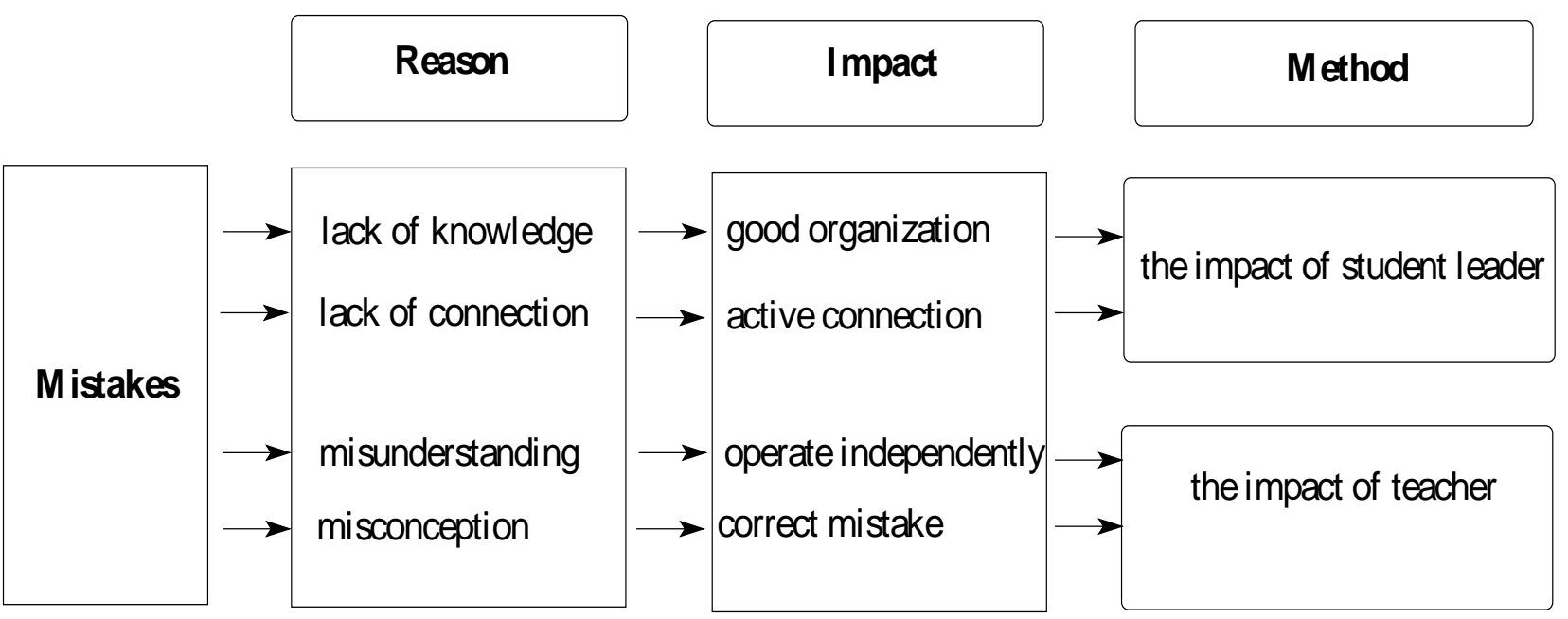

Figure 1. Keith Taber's model of error analysis in teaching 
Following Keith Taber's model above as well as Andy Chandler - Grevatt' s conception, learners' mistakes are mainly due to four reasons: lack of knowledge, lack of connection, misunderstanding or misconceptions. "The difference between a misunderstanding and a misconception is that misunderstandings often arise in the teaching and learning process. Meanwhile, misconceptions have developed outside the classroom. They are often culturally formed and strongly organized” [3].

In the same view, James $H$. McMillan shows why erroneous analysis is an essential part of effective learning and how it can be used by teachers to promote student learning [4].

The page "www.matrix.edu.au" also pointed out the eight major mistakes students make in the HSC exam in Australia's chemistry, including common mistakes the same as Vietnamese students, such as writing the wrong chemical equation, not mastering the knowledge of solubility, ... [5].

According to Andy Chandler on the famous "www.educaton in chemistry" page on Chemistry teaching, experienced teachers will discover common mistakes of learners in chemical learning. However, they do not always recognize the reasons for mistakes and remedies are often an important issue. Pinchpoint method will show the causes of mistakes of learners and allow differentiating different groups of mistakes. In addition, students can apply difficult concepts or skills more confidently into new situations [6].

In 2013, in the set of book about introductory free questions and answers for the AP exam (Advanced Placement), the authors gave an overview of each selfanswer question and how students performed on the those answers. For each question that requires students to point out fundamental mistakes [7].

In Vietnam, there have been some studies by $\mathrm{Cao} \mathrm{Cu}$ Giac, Nguyen Xuan Truong and Hoang Thanh Phong on mistakes of students during solving high school chemistry exercises, which have pointed out some mistakes when solving inorganic chemistry exercises [8]. Within the scope of this paper, we will analyze some students' mistakes through high school multiple choice exercises.

\section{Analyze Some Mistakes in the Process of Solving the Multiple Choice Questions of Chemistry}

Using the results from students' mistakes to make interferential options in multiple choice questions, will help teachers analyze the wrong situations that occur and take corrective measures. With students' mistake-based teaching methods, students will remember their mistakes and avoid repeating the same mistakes in learning.

Example 1: Acyclic compound $\mathrm{X}$ has a molecular formula of $\mathrm{C}_{4} \mathrm{H}_{9} \mathrm{NO}_{2}$. Given 10.3 grams of $\mathrm{X}$ to react sufficiently with $\mathrm{NaOH}$ solution to produce a gas $\mathrm{Y}$ and solution Z. Y gas is denser than air, causing moist purple litmus paper to turn green. Solution $\mathrm{Z}$ may discolor bromine solution. Boiling up the $\mathrm{Z}$ solution to get $\mathrm{m}$ gram of anhydrous salt. The value of $\mathrm{m}$ is
A. 8.2
B. 9.4
C. 9.6
D. 10.8

Thought Process: When solving this exercise, students often make some mistakes through the following situations:

Mistake situation 1: Students who do not pay attention to the fact that $\mathrm{Y}$ gas is heavier than air should assume that $\mathrm{X}$ is ammonium salt, deduce the structural formula of $\mathrm{X}$ is $\mathrm{CH}_{2}=\mathrm{CH}-\mathrm{CH}_{2}-\mathrm{COONH}_{4}$. The reaction equation:

$$
\begin{aligned}
\mathrm{CH}_{2}=\mathrm{CH}-\mathrm{CH}_{2}-\mathrm{COONH}_{4}+\mathrm{NaOH} & \\
& 0.1 \mathrm{~mol} \\
\rightarrow \mathrm{CH}_{2}= & \mathrm{CH}-\mathrm{CH}_{2}-\mathrm{COONa}+\mathrm{NH}_{3}+\mathrm{H}_{2} \mathrm{O} \\
& 0.1 \mathrm{~mol}
\end{aligned}
$$

Mass of salt: $\mathrm{m}=0.1$ x $108=10.8(\mathrm{~g}) \Rightarrow$ The wrong answer is D.

Mistake situation 2: Students do not consider solution Z to be able to discolor bromine solution, so $\mathrm{X}$ has a structural formula of: $\mathrm{CH}_{3} \mathrm{COOCH}_{2} \mathrm{CH}_{2} \mathrm{NH}_{2}$.

$$
\mathrm{CH}_{3} \mathrm{COOCH}_{2} \mathrm{CH}_{2} \mathrm{NH}_{2}+\mathrm{NaOH}
$$

$$
0.1 \mathrm{~mol}
$$

$\rightarrow \mathrm{CH}_{3} \mathrm{COONa}+\mathrm{HO}-\mathrm{CH}_{2}-\mathrm{CH}_{2}-\mathrm{NH}_{2}$

$$
0.1 \mathrm{~mol}
$$

Mass of salt: $\mathrm{m}=0.1$ x $82=8.2(\mathrm{~g}) \Rightarrow$ The wrong answer is $\mathrm{A}$.

The correct solution for this exercise is:

$$
\text { Because } \mathrm{X}+\mathrm{NaOH} \rightarrow \mathrm{Y} \text { (gas) }
$$

$\mathrm{Y}$ is denser than air $\left(\mathrm{M}_{\text {air }}=29 \mathrm{~g} / \mathrm{mol}\right)$ so $\mathrm{Y}$ cannot be $\mathrm{NH}_{3}$ $\Rightarrow \mathrm{X}$ has the structure formula of $\mathrm{CH}_{2}=\mathrm{CHCOONH}_{3} \mathrm{CH}_{3}$ (because $\mathrm{Z}$ is capable of discoloring $\mathrm{Br}_{2}$ solution, $\mathrm{Z}$ has double bonds $\mathrm{C}=\mathrm{C}$ ):

$$
\begin{aligned}
& \mathrm{CH}_{2}=\mathrm{CHCOONH}_{3} \mathrm{CH}_{3}+\mathrm{NaOH} \\
& \quad 0.1 \mathrm{~mol}^{\rightarrow} \mathrm{CH}_{2}=\mathrm{CHCOONa}+\mathrm{CH}_{3} \mathrm{NH}_{2}+\mathrm{H}_{2} \mathrm{O} \\
& \quad 0.1 \mathrm{~mol}
\end{aligned}
$$

Number of moles $\mathrm{C}_{4} \mathrm{H}_{9} \mathrm{NO}_{2}=10.3 / 103=0.1 \mathrm{~mol} \rightarrow$ $\mathrm{m}_{\mathrm{Z}}=0.1 .94=9.4$ (g) $\Rightarrow$ The correct answer is B.

Example 2: Add $5.6 \mathrm{~g}$ of iron powder into the excess $\mathrm{AgNO}_{3}$ solution, stir until the reaction is complete, how many grams of solids are obtained?

\section{$\begin{array}{llll}\text { A. } 24.2 & \text { B. } 21.6 & \text { C. } 32.4 & \text { D. } 10.8\end{array}$}

Thought Process: The excess $\mathrm{AgNO}_{3}$ solution so $\mathrm{Fe}$ is oxidized completely to $\mathrm{Fe}\left(\mathrm{NO}_{3}\right)_{3}$.

$$
\begin{gathered}
2 \mathrm{AgNO}_{3}+\mathrm{Fe} \rightarrow \mathrm{Fe}\left(\mathrm{NO}_{3}\right)_{2}+2 \mathrm{Ag} \\
\mathrm{AgNO}_{3}+\mathrm{Fe}\left(\mathrm{NO}_{3}\right)_{2} \rightarrow \mathrm{Fe}\left(\mathrm{NO}_{3}\right)_{3}+\mathrm{Ag} \\
3 \mathrm{AgNO}_{3}+\mathrm{Fe} \rightarrow \mathrm{Fe}\left(\mathrm{NO}_{3}\right)_{3}+3 \mathrm{Ag}
\end{gathered}
$$

From (3) $\rightarrow$

$$
\mathrm{n}_{\mathrm{Ag}}=3 . \mathrm{n}_{\mathrm{Fe}}=3 \times \frac{5.6}{56}=0.3 \rightarrow \mathrm{m}_{\mathrm{Ag}}=32.4(\mathrm{~g})
$$

$\rightarrow$ Answer is C.

Mistake situation 1: If students just stop at the chemical equation of reaction (1) and calculate because they do not know or forget that excess $\mathrm{AgNO}_{3}$ can further oxidize $\mathrm{Fe}\left(\mathrm{NO}_{3}\right)_{2}$ to $\mathrm{Fe}\left(\mathrm{NO}_{3}\right)_{3}$. From (1) $\rightarrow$

$$
\mathrm{n}_{\mathrm{Ag}}=2 . \mathrm{n}_{\mathrm{Fe}}=0.2 \rightarrow \mathrm{m}_{\mathrm{Ag}}=108 \times 0.2=21.6(\mathrm{~g})
$$

$\rightarrow$ The interferential option is B.

Mistake situation 2: If students still write the chemical equation for the reaction (3) but does not balance, leads to $n_{A g}=n_{F e}=0.1 \rightarrow m_{A g}=10.8(g) \rightarrow$ The interferential option is D. 
Mistake situation 3: If students think that solids are $\mathrm{Fe}\left(\mathrm{NO}_{3}\right)_{3}$ salts and the number of moles is equal to the number of moles of Fe so

$$
\mathrm{m}_{\mathrm{Fe}\left(\mathrm{NO}_{3}\right)_{3}}=242 \times 0.1=24.2(\mathrm{~g})
$$

$\rightarrow$ The interferential option is A.

Example 3: Which of the following substance has the lowest boiling point?
A.<smiles>Oc1ccccc1O</smiles><smiles>Oc1ccc(O)cc1</smiles>

B.<smiles>Oc1cccc(O)c1</smiles>

D.<smiles>Cc1ccccc1O</smiles>

Thought Process: Two options B and C are built similarly to the option $\mathrm{A}$, which are both benzenediol making it difficult for students to distinguish. Option D has two groups in the ortho position of each other like option A also has good interferential effects. Thus, the similarity is often confusing for students, if they do not understand the influence of intermolecular and intra-molecular hydrogen bonds on the boiling point of the substance, it is easy to be attracted by the above interferential options.

\section{Results and Discussion}

In order to evaluate the impact of the erroneous analysis in the process of solving the multiple choice questions of chemistry that positively affect the quality of teaching and learning chemistry at high schools in Vietnam, we organized to teach experimental groups and the control groups to test and analyze the scores, obtaining the following results (Table 1).

Experimental results are handled by mathematical statistical methods [9], [10] as follows: (i) Make a table of distribution of frequencies, cumulative frequency; (ii) Graph the cumulative line from the cumulative frequency distribution table; (iii) Calculate the typical parameters.
- Average value: Typical for data concentration.

$$
\bar{X}=\frac{\sum_{i=1}^{k} n_{i} x_{i}}{n}
$$

where $n_{i}$ is the frequency of $x_{i}$ values and $n$ is the number of experimental students.

Variance $\mathrm{S}^{2}$ and standard deviation S: These are parameters that measure the degree of dispersion of data around the mean value.

$$
\mathrm{s}^{2}=\frac{\sum \mathrm{n}_{\mathrm{i}}\left(\mathrm{x}_{\mathrm{i}}-\bar{x}\right)^{2}}{\mathrm{n}-1} .
$$

The smaller the $\mathrm{S}$ value, the less dispersed the data.

Standard error of $\mathrm{m}$ :

$$
\mathrm{m}=\frac{\mathrm{S}}{\sqrt{\mathrm{n}}} .
$$

The value of $\bar{x}$ will vary in the segment $[\bar{x}-\mathrm{m} ; \bar{x}+\mathrm{m}]$. Coefficient of variation of $\mathrm{V}$ :

$$
\mathrm{V}=\frac{\mathrm{S}}{\bar{X}} \cdot 100 \%
$$

- When two tables of data of two groups have equivalent values, based on the standard deviation value $S$, the group with small $\mathrm{S}$ is the better quality group.

- When the two tables of data of the two groups have different values, compare the value of $\mathrm{V}$. The group with small value of $\mathrm{V}$ is the group with more uniform quality.

To confirm the difference between 2 values $\bar{X}_{\text {Exp. và }}$ $\bar{X}_{\text {Control }}$ is significant with significance level $\alpha$, we use the $\mathrm{t}$ - Student test

$$
\mathrm{t}=\left(\bar{X}_{\text {Exp. }}-\bar{X}_{\text {Control }}\right) \sqrt{\frac{\mathrm{n}}{\left(\mathrm{S}_{\text {Exp. }}^{2}+\mathrm{S}_{\text {Control }}^{2}\right)}}
$$

Choose $\alpha$ from 0.01 to 0.05 , look at the student distribution table to find the value of $\mathrm{t}(\alpha, \mathrm{k})$ with free deviation $\mathrm{k}=2 \mathrm{n}-2$.

\begin{tabular}{|c|c|c|c|c|c|c|c|c|c|c|c|c|c|c|c|}
\hline \multirow{2}{*}{$\mathrm{N}^{\mathrm{o}}$} & \multirow{2}{*}{ Group } & \multirow{2}{*}{$\mathrm{N}$} & \multirow{2}{*}{ Test } & \multicolumn{11}{|c|}{ Score $x_{i}$} & \multirow{2}{*}{ Average Score } \\
\hline & & & & 0 & 1 & 2 & 3 & 4 & 5 & 6 & 7 & 8 & 9 & 10 & \\
\hline \multirow{4}{*}{1} & \multirow{2}{*}{ Exp. } & \multirow{2}{*}{40} & 1 & 0 & 0 & 0 & 0 & 3 & 7 & 6 & 6 & 10 & 5 & 3 & 7.00 \\
\hline & & & 2 & 0 & 0 & 0 & 0 & 2 & 7 & 8 & 10 & 6 & 5 & 2 & 6.85 \\
\hline & \multirow{2}{*}{ Control } & \multirow{2}{*}{40} & 1 & 0 & 0 & 0 & 3 & 5 & 8 & 10 & 10 & 2 & 2 & 0 & 5.83 \\
\hline & & & 2 & 0 & 0 & 0 & 3 & 4 & 7 & 11 & 11 & 3 & 1 & 0 & 5.90 \\
\hline \multirow{4}{*}{2} & \multirow{2}{*}{ Exp. } & \multirow{2}{*}{42} & 1 & 0 & 0 & 0 & 3 & 5 & 5 & 6 & 10 & 6 & 5 & 2 & 6.50 \\
\hline & & & 2 & 0 & 0 & 0 & 3 & 4 & 7 & 10 & 10 & 6 & 2 & 0 & 6.10 \\
\hline & \multirow{2}{*}{ Control } & \multirow{2}{*}{41} & 1 & 0 & 0 & 2 & 7 & 6 & 10 & 7 & 6 & 1 & 2 & 0 & 5.10 \\
\hline & & & 2 & 0 & 0 & 4 & 8 & 6 & 8 & 7 & 4 & 3 & 1 & 0 & 4.85 \\
\hline \multirow{4}{*}{3} & \multirow{2}{*}{ Exp. } & \multirow{2}{*}{40} & 1 & 0 & 0 & 0 & 2 & 5 & 9 & 10 & 6 & 4 & 3 & 1 & 6.05 \\
\hline & & & 2 & 0 & 0 & 0 & 2 & 6 & 7 & 10 & 9 & 3 & 2 & 1 & 6.00 \\
\hline & \multirow{2}{*}{ Control } & \multirow{2}{*}{41} & 1 & 0 & 0 & 2 & 5 & 8 & 8 & 7 & 7 & 3 & 1 & 0 & 5.24 \\
\hline & & & 2 & 0 & 0 & 2 & 6 & 10 & 9 & 8 & 4 & 1 & 1 & 0 & 4.88 \\
\hline
\end{tabular}

- If $\mathrm{t} \geq \mathrm{t}(\alpha, \mathrm{k})$ then the difference between $\bar{X}_{\text {Exp. and }}$ $\bar{X}_{\text {Control }}$ is significant with significance level $\alpha$.

- If $\mathrm{t}<\mathrm{t}(\alpha, \mathrm{k})$ then the difference between $\bar{X}_{\text {Exp. and }}$ $\bar{X}_{\text {Control }}$ is not significant enough with significance level $\alpha$.

Table 1. Summary of pedagogical experiment results 
Table 2. Table of frequency distribution, cumulative frequency (Lesson 1)

\begin{tabular}{|c|c|c|c|c|c|c|}
\hline \multirow{2}{*}{ Score $x_{i}$} & \multicolumn{2}{|c|}{ Number of students scoring $X_{i}$} & \multicolumn{2}{|c|}{ Percentage of students scoring $X_{i}$} & \multicolumn{2}{|c|}{ Percent of students scoring Xi or below } \\
\hline & Exp. Group & Control Group & Exp. Group & Exp. Group & Control Group & Exp. Group \\
\hline 0 & 0 & 0 & 0.00 & 0.00 & 0.00 & 0.00 \\
\hline 1 & 0 & 0 & 0.00 & 0.00 & 0.00 & 0.00 \\
\hline 2 & 0 & 4 & 0.00 & 3.28 & 0.00 & 3.28 \\
\hline 3 & 5 & 15 & 4.10 & 12.30 & 4.10 & 15.58 \\
\hline 4 & 13 & 19 & 10.66 & 15.57 & 14.76 & 31.15 \\
\hline 5 & 21 & 26 & 17.21 & 21.31 & 31.97 & 52.46 \\
\hline 6 & 22 & 24 & 18.03 & 19.67 & 50.00 & 72.13 \\
\hline 7 & 22 & 23 & 18.03 & 18.85 & 68.03 & 90.98 \\
\hline 8 & 20 & 6 & 16.39 & 4.92 & 84.42 & 95.90 \\
\hline 9 & 13 & 5 & 10.66 & 4.10 & 95.08 & 100.00 \\
\hline 10 & 6 & 0 & 4.92 & 0.00 & 100.00 & 100.00 \\
\hline$\sum$ & $\begin{array}{l}\text { Number of Exp. } \\
\text { Students (122) }\end{array}$ & $\begin{array}{l}\text { Number of Control } \\
\text { Students (122) }\end{array}$ & 100.00 & 100.00 & & \\
\hline
\end{tabular}

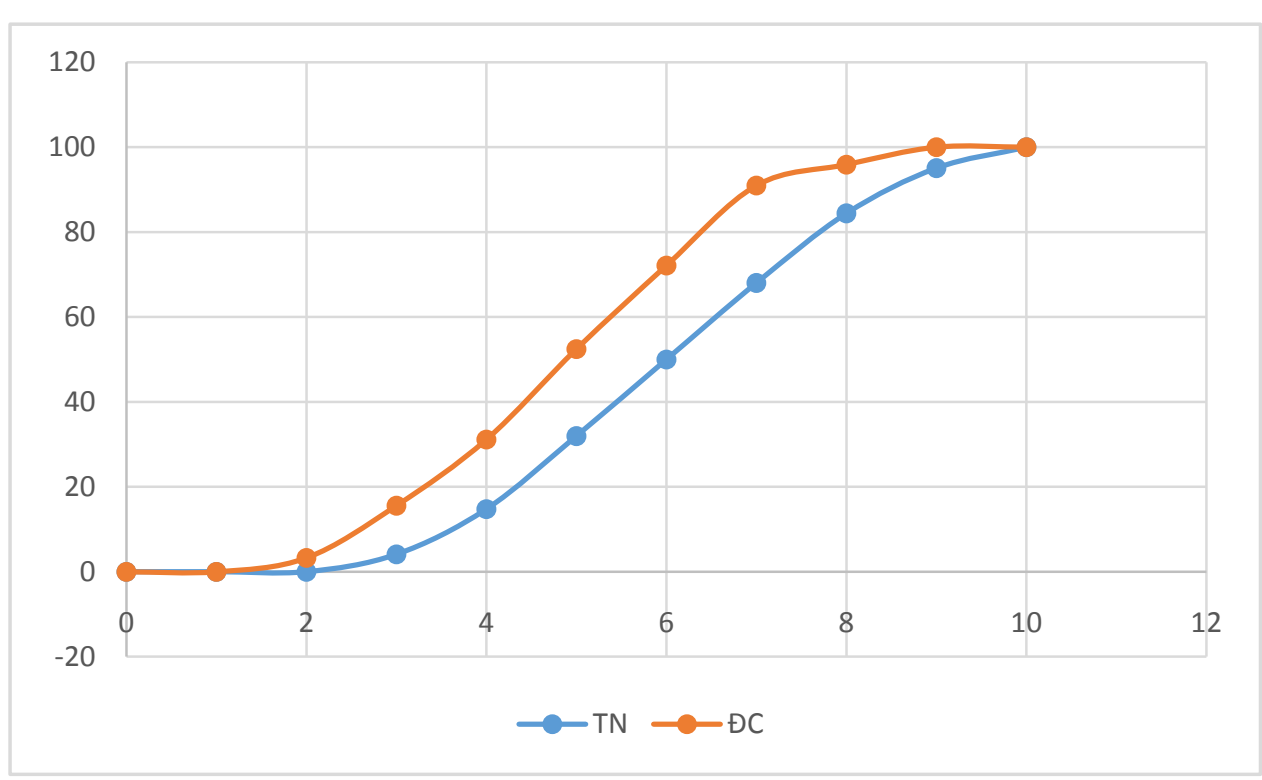

Figure 2. Percent of students scoring Xi or below (Lesson 1)

Table 3. Table of frequency distribution, cumulative frequency (Lesson 2)

\begin{tabular}{|c|c|c|c|c|c|c|}
\hline \multirow{2}{*}{ Score $\mathrm{X}_{\mathrm{i}}$} & \multicolumn{2}{|c|}{ Number of students scoring $X_{i}$} & \multicolumn{2}{|c|}{ Percentage of students scoring $X_{i}$} & \multicolumn{2}{|c|}{ Percent of students scoring Xi or below } \\
\hline & Exp. Group & Control Group & Exp. Group & Control Group & Exp. Group & Control Group \\
\hline 0 & 0 & 0 & 0.00 & 0.00 & 0.00 & 0.00 \\
\hline 1 & 0 & 0 & 0.00 & 0.00 & 0.00 & 0.00 \\
\hline 2 & 0 & 6 & 0.00 & 4.92 & 0.00 & 4.92 \\
\hline 3 & 5 & 17 & 4.10 & 13.93 & 4.10 & 18.85 \\
\hline 4 & 12 & 20 & 9.84 & 16.39 & 13.94 & 35.24 \\
\hline 5 & 21 & 24 & 17.21 & 19.67 & 31.15 & 54.91 \\
\hline 6 & 28 & 26 & 22.95 & 21.31 & 54.10 & 76.22 \\
\hline 7 & 29 & 19 & 23.77 & 15.57 & 77.87 & 91.79 \\
\hline 8 & 15 & 7 & 12.30 & 5.74 & 90.17 & 97.53 \\
\hline 9 & 9 & 3 & 7.38 & 2.46 & 97.55 & 100.00 \\
\hline 10 & 3 & 0 & 2.46 & 0.00 & 100.00 & 100.00 \\
\hline$\sum$ & $\begin{array}{l}\text { Number of Exp. } \\
\text { Students (122) }\end{array}$ & $\begin{array}{l}\text { Number of Control } \\
\text { Students (122) }\end{array}$ & 100.00 & 100.00 & & \\
\hline
\end{tabular}




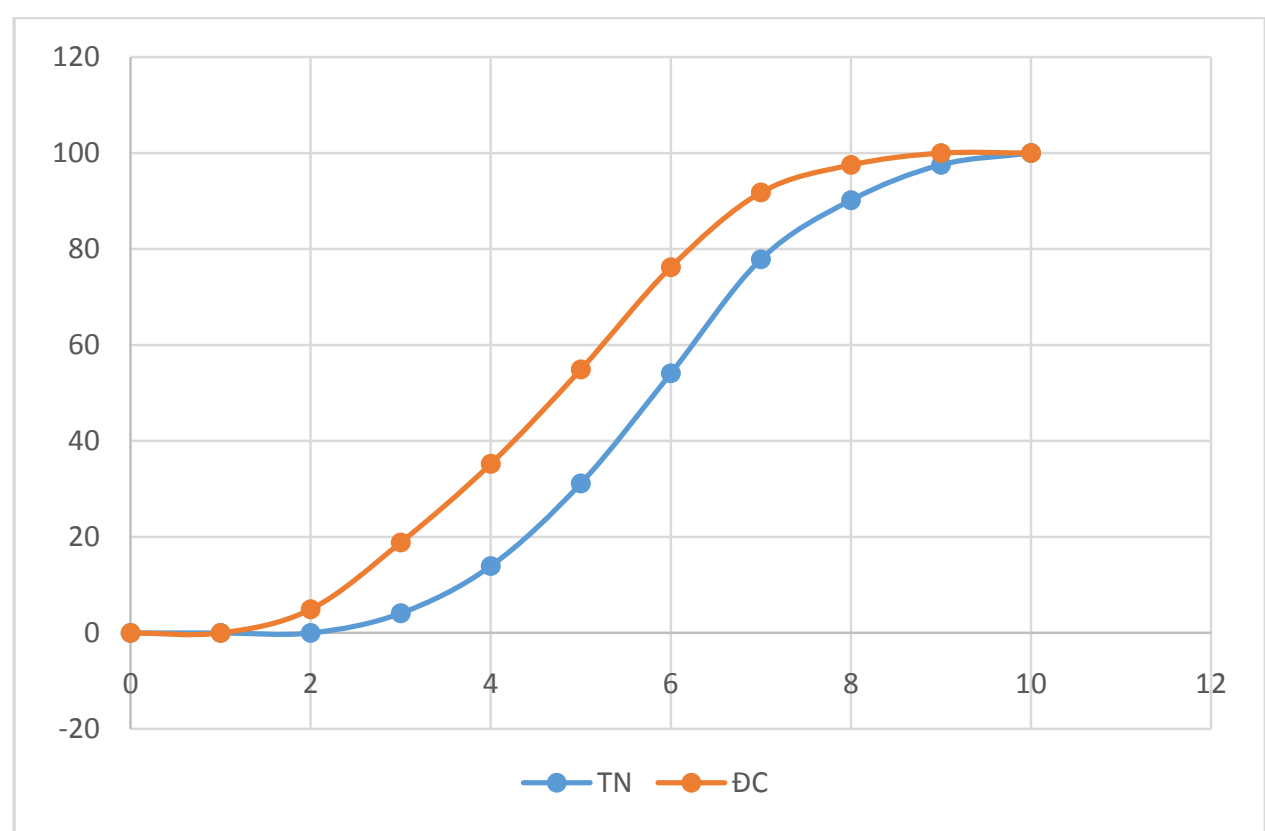

Figure 3. Percent of students scoring Xi or below (Lesson 2)

Table 4. Classification of academic results

\begin{tabular}{|c|c|c|c|c|c|c|}
\hline \multirow{2}{*}{ Test } & \multicolumn{2}{|c|}{ High } & \multicolumn{2}{|c|}{ Medium } & \multicolumn{2}{|c|}{ Low } \\
\cline { 2 - 7 } & Exp. Group & Control Group & Exp. Group & Control Group & Exp. Group & Control Group \\
\hline 1 & 61 & 34 & 43 & 47 & 18 \\
\hline 2 & 56 & 29 & 49 & 50 & 17 \\
\hline
\end{tabular}

Rules of classification: High: Score of 7 or higher; Average: Scores from 5 to 6; Low: Score below 5.

Table 5. Summary of typical parameters

\begin{tabular}{|c|c|c|c|c|c|c|}
\hline \multirow{2}{*}{ Test } & \multicolumn{2}{|c|}{$\bar{X} \pm \mathrm{m}$} & \multicolumn{2}{|c|}{$\mathrm{S}$} & \multicolumn{2}{|c}{ V (\%) } \\
\cline { 2 - 7 } & Exp. Group & Control Group & Exp. Group & Control Group & Exp. Group & Control Group \\
\hline 1 & $6.52 \pm 0.16$ & $5.39 \pm 0.14$ & 1.8 & 1.6 & 27.61 \\
\hline 2 & $6.31 \pm 0.14$ & $5.20 \pm 0.15$ & 1.6 & 1.7 & 29.68 \\
\hline
\end{tabular}

Through the results of pedagogical experiment, we found that the experimental results of the experimental group were higher than the control group, shown in:

(1) The percentage of students who achieved a low level in the experimental group is always lower than the control group and vice versa, the percentage of students achieving a high and average of the experimental group is higher than the control group.

(2) The graph of the cumulative lines of experimental group is on the right and below the graph of the control lines of the control group.

(3) The mean score of experimental group was higher than the control group.

(4) Use the student-test for 2 tests:

Test 1:

$$
t_{1}=(6.52-5.39) \cdot \sqrt{\frac{40}{\left(1.8^{2}+1.6^{2}\right)}}=2.97 .
$$

In the Student distribution table, take $\alpha=0.05$ where $\mathrm{k}=40 \times 2-2=78 \rightarrow \mathrm{t}_{\mathrm{k}, \alpha}=2.640$.

Thus, $\mathrm{t}_{1}>\mathrm{t}_{\mathrm{k}, \alpha} \rightarrow$ the difference between $\bar{X}_{\text {Exp. and }}$ $\bar{X}_{\text {Control }}$ is significant.
Test 2:

$$
t_{2}=(6.31-5.2) \cdot \sqrt{\frac{41}{\left(1.7^{2}+1.6^{2}\right)}}=3.04 .
$$

In the Student distribution table, take $\alpha=0.05$ where $\mathrm{k}=41 \times 2-2=80 \rightarrow \mathrm{t}_{\mathrm{k}, \alpha}=2.639$.

Thus,, $\mathrm{t}_{2}>\mathrm{t}_{\mathrm{k}, \alpha} \rightarrow$ the difference between $\bar{X}_{\text {Exp. }}$ and $\bar{X}_{\text {Control }}$ is significant.

\section{Conclusion}

Multiple-choice questions are widely used in the annual national high school exams in Vietnam. However, to assess the mistakes of students in the process of organizing teaching and learning in high schools, the design of multiple choice questions should focus on the results of the interference options. The analysis of the results from the erroneous situations will make the interference options strong enough to assess the effects from the mistakes. 


\section{Acknowledgements}

This research is funded by the Centre for Research Entrepreneurship Innovation, Vinh University, under contract No 04/2018/TTNC-KNST. We sincerely thank that support.

\section{References}

[1] https://www.researchgate.net/profile/Richard_Felder.

[2] Keith Taber (2014). Student thinking and learning in science. New York, NY: Routledge.

[3] Andy Chandler - Grevatt (2018), How to make the most of mistakes. Routledge Publisher
[4] James H. McMillan (2017). Using Students' Assessment Mistakes and Learning Deficits to Enhance Motivation and Learning. Routledge Publisher.

[5] www.matrix.edu.au.

[6] www.educaton in chemistry.

[7] Student Performance Q\&A: 2013 AP Chemistry Free - Response Question Chief Reader, Larry Funk of Wheaton College, Wheaton, Illinoi-USA.

[8] Cao Cu Giac, Hoang Thanh Phong (2010), “Analyze common mistakes by guiding students to solve chemistry exercises", Journal of Chemistry and Application (Topical number of scientific research results), Vietnam, No 3/2010 pp.6-9.

[9] Eichler A., Zapata-Cardona L. (2016). Empirical Research in Statistics Education. In: Empirical Research in Statistics Education. ICME-13 Topical Surveys. Springer, Cham.

[10] Schau, C., Stevens, J., Dauphinee, T. L., \& Vecchio, A. D. (1995). The development and validation of the survey of attitudes toward statistics. Educational and Psychological Measurement, 55(5), 868-875.

(C) The Author(s) 2019. This article is an open access article distributed under the terms and conditions of the Creative Commons Attribution (CC BY) license (http://creativecommons.org/licenses/by/4.0/). 